The Health Foundation, UK genevieve.cameron@health.org.uk Cite this as: BMJ 2021;375:n2629 http://dx.doi.org/10.1136/bmj.n2629 Published: 28 October 2021

\section{Less than half of the public believe the NHS has a responsibility to reduce its impact on climate change. Does it matter?}

\author{
Improving public understanding of the NHS's role in the climate crisis will help us achieve net zero \\ plans
}

Genevieve Cameron,

In a few days, world leaders will gather for the long awaited $\mathrm{COP} 26$ global climate summit. Regardless of the outcome, this will be a defining moment in the effort to solve the climate crisis.

As an industry that makes up 4-5\% of global greenhouse gas emissions, ${ }^{1}$ healthcare will feature on the packed agenda. Here, the NHS can demonstrate global leadership as the first national healthcare system with net zero commitments-to achieve net zero by 2040 for the emissions it directly controls and 2045 for the emissions it influences.

The NHS must now live up to these commitments and cut the carbon it produces from all areas of activity-buildings, equipment, supply chains, clinical practice, and more. It will take a relentless focus on the net zero target and a transformation of care at a time when the NHS faces many competing long term challenges.

Having the backing of the public will help to keep net zero plans on course. But with waiting lists at record levels, do the public care about the NHS's net zero ambitions? Through new polling published this week from the Health Foundation and Ipsos MORI, ${ }^{2}$ we sought to gain a comprehensive picture of public opinion on climate change and the NHS.

\section{What the public think about climate change and the NHS}

Our polling shows that the public see climate change and health as closely entwined. There is widespread belief that climate change threatens the health of people globally $(86 \%)$ and in the UK $(73 \%)$. A quarter see climate change as one of the biggest threats to their own health. Strikingly, climate change is seen as significant a risk to health as accidents/injuries and mental health problems.

But the NHS's role as a significant contributor to the risk of climate change is not clearly recognised. Only around a quarter of people $(26 \%)$ believe the NHS is contributing to climate change, while nearly a fifth $(19 \%)$ disagree. Less than half (44\%) believe that the NHS has a responsibility to reduce its impact on climate change.

\section{Harnessing public support}

Does it matter if the public do not clearly see the NHS as part of the climate change problem? Our polling suggests that it's not necessarily a barrier to support for net zero plans. The majority of people (70\%) support the net zero NHS target. Just $6 \%$ oppose it.
Public support for the long term net zero target is important, but it is the actions that really matter. We found broad support for a range of measures to get to a net zero NHS-even if trade-offs are required. Around two thirds (65\%) of people support providing more environmentally friendly food in hospitals, even if this means they have less choice. Most people support switching to low emission ambulances $(63 \%$ support) and building new hospitals to net zero standards (6o\% support), even if tax must increase to pay for it.

More encouraging still, we found that people are willing to change their own behaviour to support a net zero NHS. More than nine in 10 (91\%) would return unused medications and $85 \%$ would accept reusable equipment. This knowledge-which proposals have strongest support and can be enabled by public behaviour change-should be used to inform and facilitate the implementation of net zero plans.

\section{Overcoming barriers}

While the public generally support the net zero ambition, it is not high on their list of priorities for the NHS for the next 10 years. Reducing waiting times, hiring additional staff, and improving staff morale and reducing burnout are the public's top priorities. Minimising the impact on climate change was ranked second from the bottom of the 15 priorities considered. Aligning net zero plans to wider NHS objectives could help to maintain focus on the task of honouring climate change commitments.

We also found that public support appears to fall for measures to reduce emissions that are seen to have an impact on individual treatment decisions and care. For example, more people oppose (35\%) than support $(30 \%)$ the NHS considering environmental impact when deciding what treatments to offer. Thirty per cent would not be willing to opt for a remote GP consultation (to reduce travel, rather than seeing a doctor in person). Public engagement will be needed to resolve tensions between environmental impact and individual needs and preferences wherever these arise.

Finally, we found that only $27 \%$ of the people surveyed who personally work in the NHS were aware of the net zero ambition. A fully engaged NHS workforce is critical to delivering net zero plans, so building staff awareness is an essential task.

The NHS net zero ambition has broad public support. This is a boost for the net zero agenda and can inform bold action to deliver on its plans. However, some 
ambivalence among the public risks net zero slipping down the NHS's priorities. Currently, the public do not appear to have strong feelings about the NHS's responsibility to address climate change and they see bigger priorities for the NHS over the next 10 years. Maintaining momentum around the aim of achieving a net zero NHS will require sustained work to engage staff and make the case to the public for why the NHS's role is critical to fixing the climate crisis.

Competing interests: none declared.

1 Karliner J, Slotterback S, Boyd R, Ashby B, Steele K. Health care's climate footprint. How the health sector contributes to the global climate crisis and opportunities for action. Health Care Without Harm. 2019. https://www.arup.com/perspectives/publications/research/section/healthcares-climate-footprint

2 Public polling on climate change and health. Conducted by Ipsos MORI for The Health Foundation. Oct 2021. https://www.health.org.uk/publications/public-perceptions-of-climate-change-andhealth-september-2021 